\title{
Investigation of Using Mobile Phones with RFID Technology for Automation and Access Control Systems in Smart Buildings
}

\author{
Esra Bayır ${ }^{1}$
}

\begin{abstract}
Wide choices of the name of making life easier for users of developing technologies, are increasing the demand for smart buildings day by day. Therefore, smart budings producing new solutions by be integrated to develpoing technologies, has become a condition to accelerate in order to respond growing demand and led producers to new and more advanced searches. Automation and other systems in the smart buildings can not satisfy the need to user requirements as required, despite of fast development in information and innovative technogies. Near field communication (NFC) which aims to establish a short-range communication, is a new technology. NFC allows correspondence of electronic devices via a magnetic field with Radio Frequency Identification (RFID). In this paper, NFCenabled mobile phone as a new approach to the alternative preferred to card access systems in the smart buildings is emphasized on what improvements and advantages for users and manufacturers.
\end{abstract}

Keywords - smart buildings, card access systems, RFID, NFC.

\section{INTRODUCTION}

Nowadays, rapidly increasing number of high-rise buildings arouse interest with magnificence external and are proud on distinction of being smart buildings. However, when these buildings are evaluated in terms of providing opportunitiesadvancement of technology and comparisons results made with other smart building-, the fact that the smart buildings fed by the new technology is revealed.[1,2] Which perspective do smart buildings become more inrelligent? Do smart buildings, offering high-tech opportunities provide most suitable condition for users or offer advanved technology opportunities of time and cost for architectures and engineers in the process of design and construction? From these points forth in this paper, facilities of using NFC (aims to bring practical solutions with developing technology for users in the smart buildings) compatible mobile phone in the systems of smart building and card access, will be emphasized.

\section{SMART BUILDINGS}

Smart buildings having a lot of descrptions are possible to observe into three groups based on the performance, service and system. Smart building Institute (IBI) in USA make a description based on performance by justifing that a building should ensure extremely efficient, comfortable and appropriate environmental conditions to provide the four basic demands, such as management, service, system, structure. Morever, Japon Smart building Institute (JIBI) makes a decription based on service by defending that these buildings with the ability of integrated smart activities carry functions of building automation, office automation and communication services. Some experts and system developers use a definition based on system that building automation (BA), communication automation (CA) and office automation (OA) represent IB on three principle. $[1,3,4]$ According to all descriptions, advanced facilities which play an active role on behalf of making life easier for individuals and organizations by in process of design, construction and using, determines whether or not a building is smart. At the beginning, IB is designed to contribute for office structure, but today IB services to structure having different functions such as business centers, hospitals, schools, commercial buildings, shopping centers, sports-living centers, residences, hotels, banking centers, government offices. [5]

Generally, IB have benefits like energy, time, saving labor; to provide the most rapid and comfortable working and living spaces; high safety and low operating costs with maximum efficiency and minimum personnel control and management of buildings.

However in last research of Building Operators and Managers Association (BOMA), it is emerged the result of neccessary providing to users essential features such as fiber optic capacity, internet access to the entire building, highspeed computer network, LAN-to-WAN communications, satellite access, redundant power supply, high-tech and energyefficient heating-cooling-ventilation (HVAC) system, sensor reinforced centrally controlled lighting system, smart lifts, automatic sensor faucets and toilets in practice and computeraided facility management. [2,5,6]

\subsection{Smart Building Systems}

IB systems are complicated systems that synchronize in the form of integrated many sub-system (mechanical and electronic), are managed and controlled by a single center automation and also are integrated to new technologies by itself in the future.[7] To be IB, essential systems like air conditioning, fire detection, security, lighting, elevators, power control, access control must work according to the principles of smart work and manage other IB subsystems efficiently.[8] (Figure 1) 


\begin{tabular}{|c|c|c|c|c|c|c|c|c|c|c|c|c|c|c|}
\hline level 4 & \multicolumn{10}{|c|}{ SMART } & \multicolumn{4}{|c|}{ BUILDINGS } \\
\hline level 3 & \multicolumn{10}{|c|}{ integrated building management system } & \multicolumn{4}{|c|}{ integrated communications } \\
\hline & \multicolumn{10}{|c|}{ subsystem } & \multicolumn{4}{|c|}{ subsystem } \\
\hline level 2 & \multicolumn{4}{|c|}{ safety security } & \multicolumn{3}{|c|}{ environmental control } & \multicolumn{3}{|c|}{ power management } & sound & \multicolumn{2}{|c|}{ image } & Data \\
\hline level 1 & 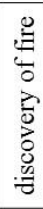 & 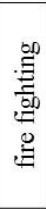 & 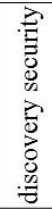 & 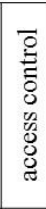 & $\sum_{n=1}^{\infty}$ & $\stackrel{U}{\grave{I}}$ & 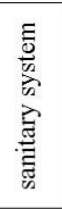 & 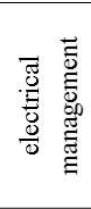 & $\begin{array}{l}\text { 兽 } \\
\text { 总 }\end{array}$ & 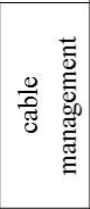 & $\begin{array}{l}\stackrel{0}{0} \\
\frac{0}{0} \\
\stackrel{0}{0} \\
\frac{7}{\pi}\end{array}$ & 己 & $\frac{\stackrel{x}{0}}{\stackrel{0}{巳}}$ & 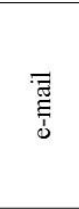 \\
\hline & \multicolumn{10}{|c|}{ building service functions } & \multicolumn{4}{|c|}{ communication } \\
\hline
\end{tabular}

Fig 1: IB Systems [2]

Having many different subsystems, IB systems can be grouped as follows; building automation systems, building management; security and user identification systems; access and transportation systems; sound and video systems; information and communication systems; lighting and lighting automation systems, air conditioning (HVAC) and air conditioning automation systems, power supplies and cabling. [7] In particular, integrated security and access systems is crucial in terms of all data transferred easily and quickly when needed. (Figure 2)

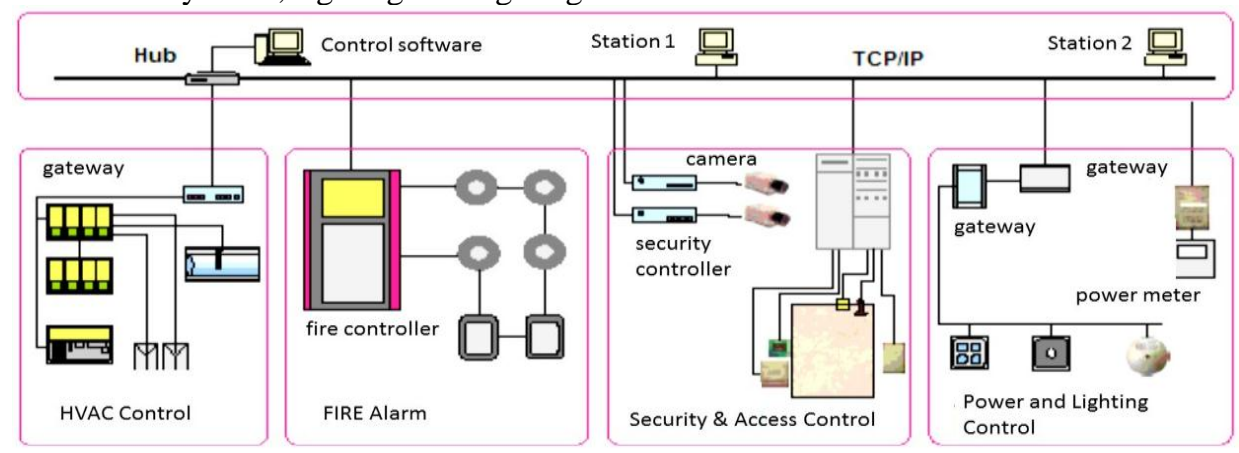

Fig 2: IB Automation System Management [9]

\subsection{Security and User Identification Systems}

Security systems firstly are constituted to prevent problems may ocur inside of building before they form. Burglar, fire, smoke, gas detection and prevention systems, various detectors, closed circuit television cameras and card access systems are some of them.

Furthermore, avaliable main security and user idendification subsystems are integrated security systems, burglar detection and security systems, fire and smoke detection and alarm systems, fire extinguishing systems, gas detection and alarm systems, closed-circuit camera and television security systems (CCTV), metal and x-ray detectors, access control and user detection systems, perimeter security systems and water, air control systems.

\subsection{Card Access Control Systems in IB}

User idendification systems can be said that they have emerged with card access systems for the first time. Early, Card access have been used to control employee ID and prevent access of stranger to building. [7] Entrance-exit control systems are the most important part of securtiy system.

These systems have been set up to serve needs such as controlling the entrance-exit to the building, keeping the records of entrance-exit in time domain, receving reports retroactively, the authorization of entry and exit to this area, ensuring the safety of navigation in the area for visitors, regulation and recording entry and exit of visitors, determining the location of people walking around and being in building at that moment. [5] Additionally, a lot of types of securtity system are used in IB like (CCTV) camera and video systems, card access systems and biometric systems. (Figure 3-5)

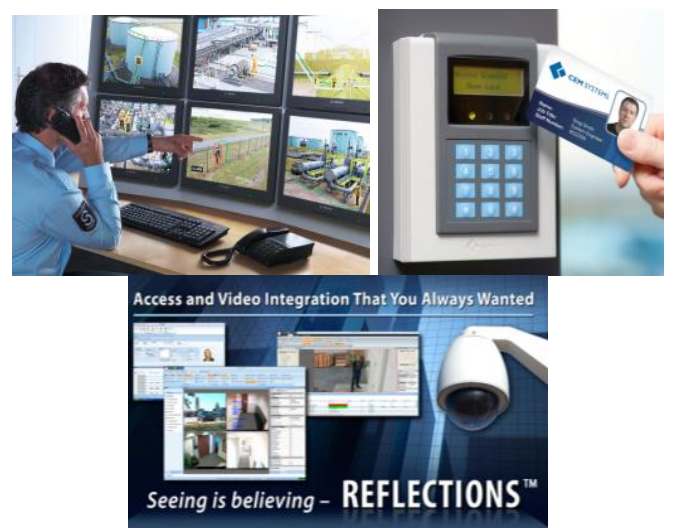

Fig. 3-4-5: Building Access Control Systems [10-12]

Card access systems are utilized densely at the limited transition doors in building/facility, turnstiles, entrance and exit of garage, cafeteria entrance, etc. Equipments, compliance with the architectural layout and security scenarios to be created for human trafficking are preferred in determined point in the building. Expandability and flexibility will be essential in the design of card access systems. System uses the technigue of distributed data processing based on microcomputer. If required, current scenario should be changed easily only software changes. Also, these changes should be easy to add equipments such as card reader, lock, 
turnstile, etc in terms of system architecture and cabling for needs in the future. Besides, card access panels use LAN network system (Local Area Network) for communication. Card access system consists of the folllowing subunits;

\section{System type}

System has weak current working with proximity and mifare card reader. It consist of the integration of subsystems just as access control panel, LAN communication modules, card readers, cards, magnetic contact, door control button, power door locks, magnetic door locks, half height turnstiles, full height turnstiles and injured crossing Gates.

\section{System equipments}

The necessary equipment are card access control panels, LAN communication modules, card readers, cards, magnetic contact, door release button, power door locks, magnetic door locks, half height turnstiles, full height turnstiles and gates injured crossing.

\section{Wiring and Network Infrastructure}

Network provides communication with LAN communication modules, operator stations and PC in the system. Thus, LAN be designed, will specify in accordance with all needs of system. $[1,13,14]$

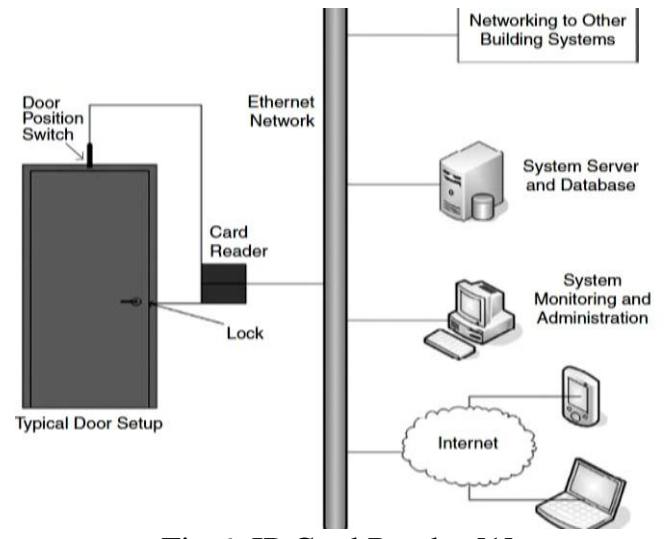

Fig 6: IP Card Reader [1]

Card access system has different cards according to card reader method (contact-contactless cards) and working principle (conventional and smart cards). Some of these cards are;

Magnetic cards; are the card type usually used for access control and particularly banking applications wtih a magnetic stripe. MC has become the most popular card within compatible cards with credit cards because of variety of MC.

Wiegand cards; are commonly used in access systems as credit cards and work as regards a method similar to working principle of magnetic cards. Morever, they are the most ideal card in the field due to rapidly respond time and portable.

Proximity cards; are widespreadly used another contactless cards. They usually work with high-grade fiberglass-epoxy board embedded integrated circuits (IC).

Smart cards; are consist of integrated chips embedded in the plastic surface. They ensure a higher level of security than traditional cards. Furthermore, they allow a safe reading and writing data. $[13,14]$

\subsection{Biometric Access Control}

Occasionally used biometric systems are hand geometry, fingerprints, palm prints, voice recording, face recognition, iris recognition and signature verification. Because of high reliability and faultless calculation ability, biometric recognition systems are intensively demanded in the field of access security systems. [1]

When current structures are considered, it is understood card system how much prefered owing to be first. For example; Contactless-Smart Cards have been used for card access control system in company with Philips - Hitachi in İstanbul Metrocity Buildings. As card reader, Mifare readers compatible with system have been utilized. [7]

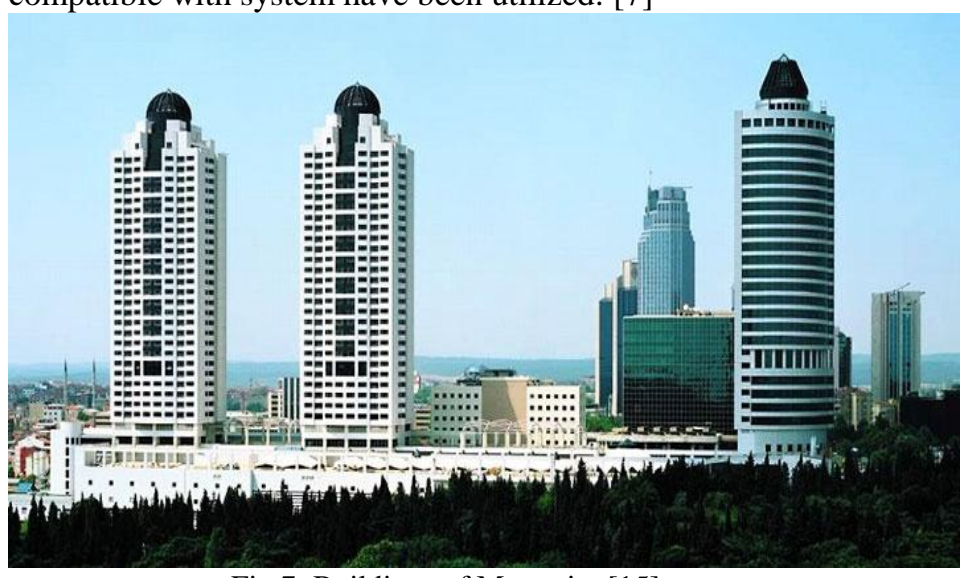

Fig 7: Buildings of Metrocity [15]

\section{NEAR FIELD COMMUNICATION (NFC) TECHNOLOGY}

Near Field Communication, NFC is a technology based on Radio Frequency Identification, RFID. It supplies wireless communication in short distance by making possible correspondence of two NFC compatible devices on a secure radio frequency interface. [17,18] NFC, designed for interactions- very short distance $(0-4 \mathrm{~cm})$ or in formed adumbrating two electronic devices each other, provides data communication on high frequency (13:56 MHz) and low bandwidth (424 kbit/s).[19] Morever, ensuring data communication in very short distance is an important advantage for securtiy.

NFC has more basic hardware, more easier using and less power consumption than other technologies (Bluetooth, Wifi, Wibree, Zigbee, Ir DA etc) in short distance communication. [16] Bluetooth wireless technology was designed to replace cables between cell phones, laptops, and other computing and communication devices within a 10-meter range. Wi-Fi technology was designed and optimized for Local Area Networks (LAN); it provides an extension or replacement of wired networks for dozens of computing devices within a +100 -meter range. ZigBee wireless technology is a standard enabling control and monitoring capabilities for industrial and residential applications within a +100 -meter range. $\operatorname{IrDA}$ is a short range (<1 meter), line-of-sight communication standard 
for exchange of data over infrared light. IrDA interfaces are frequently used in computers and mobile phones. [18]

NFC also can contact in a short time and hardware is more cheaper than other wireless technologies. Today's most widely used portable devices, mobile phones are the most important devices as a candidate to be used for NFC reader. Besides, NFC compatible mobile devices can read and storage data over NFC tag.

Owing to be integrated to mobile devices, a popular technology NFC have been paved the way applicatied in many areas is last years. Contactless payment systems and contactless ticketing systems allow users for making payment with their NFC compatible smart mobile phones without carry more than one card. [16] Morever, smart posters applications provide easy using for functions as smart university systems, remote patient follow-up, remote meal order by moving tag data to mobile phone after zooming from mobile phones to posters. [20]

NFC specially are clear to produce new solutions for healthcare. For instance, NFC can ensure storing patient story in mobile phone instead of hospital servers. What is more, the truth of offering new solutions integrated to lots of areas has made NFC a wanted technology. [21]

\section{NFC Working Principle}

NFC eco-system consisting of active and passive devices has three different operating modes included in one to one work mode, reader-writer operation mode and card emulation operation mode. While NFC tags can be hold up as passive devices, NFC readers and NFC compatible mobile devices can be example for active devices. The following table describes the NFC operating modes and applications. [16,22]

TABLE I: NFC operating modes

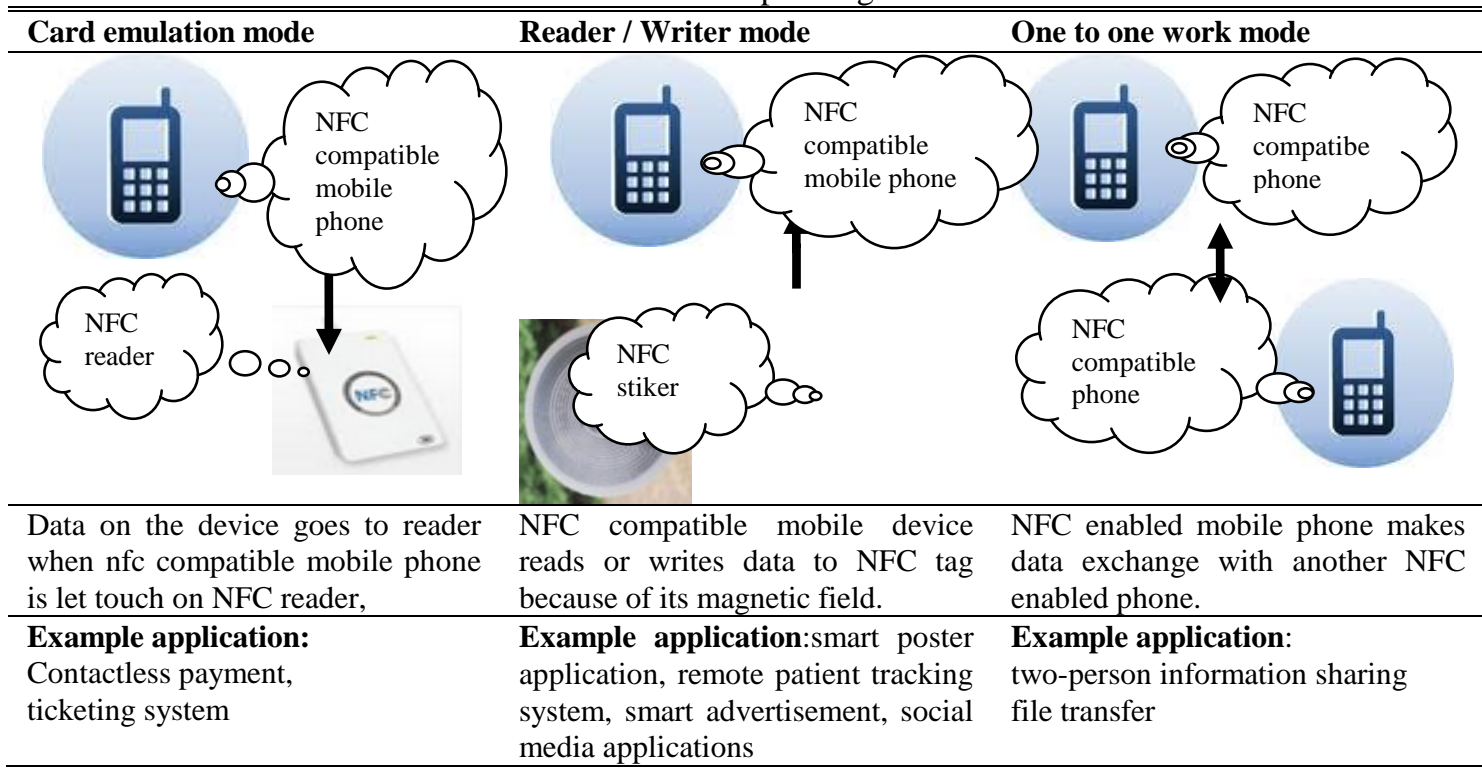

Result of literature search, it has seen that academic studies are intended for research about NFC generally. But, application studies have increased last years. too. Due to the fact that any academic researh or application study about the use of NFC technology in smart buildings could not be coincided in the literaure, the proposal for the usage of NFC technology in Smart building is a new approach.

\subsection{Usage of NFC Technology in IB Systems}

Application of NFC compatible mobile phones in IB systems which aim to gather many subsystems as integrated, is one of the best candidate to serve this purpose. Because of NFC tags in various location of building, control of building interior systems can be possible with mobile phone.

Thanks to NFC tags in IB layers and different location on layers, users can run distinct air-conditioning settings at another point and store optimum temperature for themselves on their phones, also later, make the same settings active again. Fire alarm systems can be brought more efficient condition due to NFC tags. Thus, user can touch the naerest tag with phone if there is a fire and also can directly interfere to the point where the fire is, by transmitted the information of tags location to related centers. So, fire can be provided intervention opportunity more quickly and in less time.

Morever, if these tags are used in elevators, it can be prevented using the elevator of unrelated people and malfunction can be determined in which elevator with emergency tag of elevator, also can be interfered to elevator as soon as possible by transmitting the knowledge of malfunction to relevant unit.

In access systems, users can be given different permissions thanks to authorisations descripted to NFC compatible phone. For instance, visitors can be prevented to use building out of their descripted time with knowledge of limited day and time identified to phone for guests. Additionally, NFC tags in building can be used in case of any burglar. User can convey the location of burglar to securtiy by making touch phone to NFC tag and also burglar can be prohibited to run away by locking exits of relevant floors.

Furthermore, with smart posters in IB, communication can be eaiser between building management and residents. NFC operating modes of IB systems are shown on Table 2. 
TABLE II: NFC operation modes in IB systems

\begin{tabular}{ll}
\hline \hline Smart Building System & NFC modes of work \\
\hline Air-conditioning & Reader/Writer operation mode \\
Fire Alarm & Card emulation operation mode \\
Elevators & Card emulation operation mode \\
Passing Authorization & Reader/Writer operation mode \\
Burglar sensation and security & Card emulation operation mode \\
Building Internal Social Media & Reader/Writer operation mode \\
Application & \\
\hline
\end{tabular}

\subsection{Usage of NFC Technology for Card Access Control Systems in IB}

Nowadays, rapidly expanding on mobile phone fingerprint recognition, iris recognition and face recognition technology, combined with advanced technologies such as NFC in case of inretgrated IB security and access systems, all systems can be gathered with a phone and tag. By this means, the costs can be reduce significantly for users and manufacturers by being abolished card cost.

With the use of NFC technology, rather different reading and recognition systems only usage of NFC tag has still a substantial advantage in terms of cost. Morever, NFC technology allows security and access control systems rapidly, easily and together working. Besides, NFC-enabled mobile phones, adding new solutions over all functions of card access systems offer a new cheap, fast and easy access system.

Control of building entrances-exits and user-based authorization of entry-exit in some areas of the building are idendificated to NFC-enabled mobile phones. Also, access history of building personnels can be stored in phone on the basis of time. If user, entering to building with NFC compatible phone, gets on the elevator, it can be determined where elevator's floor because of NFC tags on elevator.

Another advantage of collecting all systems in a single phone is to eliminate the need to carry a card. Card, due to their material, the added software and microchips on it, tends to increase its cost. Whereas, if NFC enabled phone is used, card cost will be removed and likewise the cost increase that may arise due to card itself, will be eliminated.

\section{RESULt}

In this paper, a new system proposal is brought forward by referring to current smart building technologies and emphasing on integrated these systems wtih new technologies.

Near Field Communication (NFC), based on Radio Frequency Identification (RFID) suppling wireless communication in short distance by making possible correspondence of two NFC compatible devices on a secure radio frequency interface, has been researched usage in access control systems and other smart buildings subsystems and evaluated in terms of providing more progressive solutions than current systems.

A new approach NFC compatible smart mobile phones preferred as an alternative to the smart building and card access control systems, provides advantages such as cost reduction, combining all current available technologies (face recognition, touch screen, access control, fingerprint recognition), gathering under a single roof security and distributed systems for users and manufacturers.

Consequently; NFC compatible mobile phones have been proposed to provide more practical and comfortable solutions for users by emphasizing the importance of adapting developing technologies to smart building. Because of not coming accross any study about RFID and architecture before, the proposal for the usage of NFC technology in Smart building is to be a new approach.

This study can also lead another researhes related automation systems by following new and developing technologies, and trying usage of another devices with another systems in buildings or houses.

\section{REFERENCES}

[1] J. Sinopoli, Smart Building System For Architects, Owners and Builders, Elsevier, 2010, pp. 3

[2] H. Kiliç, "Smart Buildings, Installitaion and Operating", M.S. thesis, İstanbul Technical University, Institute of Science, Operating Engineering, Turkey, İstanbul, 2007

[3] S. Wang, Smart buildings and Building Automation, Spon Press, London and New York, USA, 2010

[4] A. Ghaffarianhoseni, N. Makaremi, M. Ghaffarianhoseini. The Concept of Zero Energy Smart buildings (ZEIB): A Review of Sustainable Development for Future Cities. British Journal of Environment \& Climate Change. 2012. 2(4). pp. 346

[5] M. Sönmez, "Technical-Technological Systems of Smart buildings And Integration of Energy Monitoring System", M.S. thesis, İstanbul Technical University, Institute of Energy, Energy Science and Technology Programme, İstanbul, Turkey, 2006

[6] D. Clements, What Do We Mean By Smart Buildings?, The University of Reading, School of Construction Management \& Engineering, UK, 1997

[7] B.C. Arabacioğlu, "Smart Buildings Systems with Inteactively Personalizable Interior Space and A Model Proposal for Process of Intelligent Interior Design of the Future", Proficiency in Art thesis, Mimar Sinan Fine Arts University, Institute of Science, Interior Architecture Department, İstanbul, Turkey, 2005

[8] L. Eng Loo, "Smart Building Automation System", University of Southern Queensland, Faculty of Engineering and Surveying, Bachelor of Mechanical Engineering, Course ENG4111 and 4112 Research Project, 2006

[9] O. Oğuz, "Smart Buildings and Smart Building Evaluation Methods", M.S. thesis, İstanbul Technical University, Institute of Science, Architecture, Turkey, İstanbul, 2007

[10] Communication and Security Systems -Kocaeli, 2014 [/www.iletsel.com.tr/]

[11] Access Control Upgrade for Auckland Airport, 2014 [/www.asiapacificsecuritymagazine.com/]

[12] Revolutionary Marriage of Access Control and Video System, 2014, [/www.kerisys.com/]

[13] Card Access Specification, 2016, [www.sibertek.com.tr/dosyalar/urunler/pdf/KARTLI_GE_GENEL_AR TNAMES.doc]

[14] Card Access Control Systems, 2016, [http://www.netwell.com.tr/]

[15] An Overview Condominiums in Turkey in the context Rising Structure, 2014 [/ www.yapidergisi.com/]

[16] B. Özdenizciok, M.N. Aydin, V. Coskun. Review of Near Field Communication Technology. Journal of BBM. 4 (1). pp. 85-92. 2011

[17] J. Ylinen, M. Koskela, L. Iso-Anttila, P. Loula, "Near Field Communication Network Services", in Proc. Digital Society, ICDS '09 3rd International Conference, 1-7 February 2009, pp. 89-93 https://doi.org/10.1109/icds.2009.43

[18] Near Field Communication Forum, (September 2016), [http://nfcforum.org/] 
[19] K. Ok, V. Coskun, M.N. Aydin, B. Özdenizci, "Current Benefits and Future Directions of NFC Services", in Proc. of IEEE International Conference on Education and Management Technology, 2010 https://doi.org/10.1109/icemt.2010.5657642

[20] I.L. Ruiz, M.A. Gomez-Nieto, "University Smart Poster: Study of NFC Technology Applications for University Ambient", in Proc. 3rd Symposium of Ubiquitous Computing and Ambient Intelligence, Salamanca, Spain, Springer, 2008

[21] N. Akalin, A. Özturk, M.N. Aydin, "Application of NFC Technology on e-health Applications", in Proc. 2nd International Conference on Informatics, ICI' 2011, Çanakkale, Turkey, April 2011

[22] NFC Research Lab in Hagenberg, 2016, [http://www.nfc-research.at/] 